\title{
STUDIES ON THE SEPARATION OF MINOR ACTINIDES FROM HIGH-LEVEL WASTES BY EXTRACTION CHROMATOGRAPHY USING NOVEL SILICA-BASED EXTRACTION RESINS
}

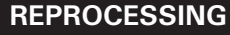

KEYWORDS: minor actinides, silica-based extraction resins, Cyanex 301

\author{
YUEZHOU WEI,* MIKIO KUMAGAI, and YOICHI TAKASHIMA \\ Institute of Research and Innovation \\ Nuclear Chemistry and Chemical Engineering Center \\ 1201 Takada, Kashiwa 277-0861, Japan
}

GIUSEPPE MODOLO and REINHARD ODOJ

Forschungszentrum Jülich GmbH, Institute for Safety Research and Reactor Technology D-52425 Jülich, Germany

Received February 7, 2000

Accepted for Publication June 9, 2000

To develop an advanced partitioning process by extraction chromatography using a minimal organic solvent and compact equipment to separate minor actinides such as Am and Cm from nitrate acidic high-level waste (HLW) solution, several novel silica-based extraction resins have been prepared by impregnating organic extractants into the styrene-divinylbenzene copolymer, which is immobilized in porous silica particles $\left(\mathrm{SiO}_{2}-\mathrm{P}\right)$. The extractants include octyl(phenyl)-N, N-diisobutylcarbamoylmethylphosphine oxide (CMPO), di(2ethylhexyl)phosphoric acid (HDEHP), and bis(2,4,4trimethylpentyl)dithiophosphinic acid (Cyanex 301). Compared to conventional polymer-matrix resins, these new types of extraction resin are characterized by rapid kinetics and significantly low pressure loss in a packed column.

The results of separation experiments revealed that trivalent actinides and lanthanides can be separated from other fission products, such as Cs, Sr, and Ru in simulated HLW solution containing concentrated nitric acid by extraction chromatography using a CMPO/SiO ${ }_{2}-\mathrm{P}$ resin-packed column. Satisfactory separation between Am(III) and a macro amount of lanthanides from simulated HLW solution with $\mathrm{pH} 4$ was achieved by using a newly purified Cyanex 301/SiO ${ }_{2} P$ resin. However, the Am(III) separation was very sensitive to the purity of Cyanex 301, and the improvement of its stability is an important task for practical utilization.

\section{INTRODUCTION}

In the PUREX process, the long-lived minor actinides (MA) such as Am and Cm are generally produced together with various fission product elements (FPs) as high-level waste (HLW) containing concentrated nitric acid. As a final disposal method for HLW, the geologic disposal concept of vitrified HLW has been proposed and investigated worldwide. On the other hand, from the viewpoints of minimizing the long-term radiological risk and facilitating the management of HLW, an isolation of the

\footnotetext{
*E-mail: yzwei@iri.or.jp
}

long-lived MA from HLW is much more desirable. For this purpose, a number of partitioning processes (e.g., TRUEX, TRPO, DIDPA, and DIAMEX) have been developed in recent years. ${ }^{1-7}$ However, all these processes essentially utilize liquid-liquid extraction technology by using a mixture of an organic extractant and a hydrocarbon diluent. A large amount of the so-called secondary waste, which is difficult to treat and dispose of, will be generated by the extraction process. In addition, the liquidliquid extraction process is basically only beneficial for a large-scale process. ${ }^{8,9}$ Compared to $\mathrm{U}$ and $\mathrm{Pu}$, the minor actinides are significantly less abundant in the spent fuel, so the scale of the separation process for minor actinides 
from HLW should be considerably smaller than that of the PUREX process.

As an alternative method of reprocessing spent nuclear fuels, in recent years we have been investigating an advanced ion exchange process using a novel silicabased anion exchanger. ${ }^{10-13}$ In the column separation experiments using simulated spent-fuel solutions, Am(III) and $\mathrm{Cm}$ (III) showed no adsorption onto the anion exchanger and leaked out together with most of the FPs, such as $\mathrm{Cs}(\mathrm{I}), \mathrm{Sr}(\mathrm{II})$, and trivalent lanthanides [Ln(III)]. This HLW stream contains approximately 3 to $6 M(1 M=$ $\left.\mathrm{mol} / \mathrm{dm}^{3}\right) \mathrm{HNO}_{3}$.

To develop an advanced partitioning process by extraction chromatography, which utilizes a minimal organic solvent and compact equipment to separate the minor actinides from the nitrate acidic HLW, we have prepared several novel silica-based extraction resins by impregnating an organic extractant into the styrenedivinylbenzene copolymer, which is immobilized in porous silica particles. Compared to the conventional polymeric matrix resins, these new types of extraction resin are characterized by rapid adsorption-elution kinetics, high mechanical strength, and significantly low pressure loss in a packed column. The extractants employed were octyl(phenyl)-N, N-diisobutylcarbamoylmethylphosphine oxide (CMPO), di(2-ethylhexyl)phosphoric acid (HDEHP), and bis (2,4,4-trimethylpentyl)dithiophosphinic acid (Cyanex 301). Figure 1 shows the chemical structures of these extractants. CMPO has been reported to have a strong extracting ability for trivalent actinides and lanthanides from highly acidic solution. ${ }^{14,15}$ HDEHP is well known as a selective extractant for the separation of lanthanides. Cyanex 301 is a commercial extractant, ${ }^{\mathrm{a}}$ and its purity is 75 to $85 \%$. Recently Zhu et al. ${ }^{16,17}$ reported that the purified Cyanex 301, which contains sulfur atoms as the soft donor, is an excellent extractant for the separation of Am(III) from Ln(III).

This paper describes the preparation procedure for the novel silica-based extraction resins and their adsorption characteristics for $\mathrm{Am}$ (III) and $\mathrm{Ln}$ (III) in nitrate acidic solutions. Furthermore, the separation behavior of Am(III), Ln(III), and other typical FPs from simulated HLW solutions is demonstrated by column chromatography. Based on the experimental results, an advanced partitioning process is proposed for the isolation of the minor actinides from a nitrate acidic HLW stream using these new types of extraction resin.

\section{EXPERIMENT}

\section{Preparation of Silica-Based Extraction Resins}

Spherical silica particles ${ }^{\mathrm{b}}$ with a diameter of 40 to $60 \mu \mathrm{m}$, a mean pore size of $600 \mathrm{~nm}$, and a pore fraction

\footnotetext{
${ }^{a}$ From Cytex Canada.

${ }^{\mathrm{b}}$ From Asahi Chemical Industry.
}

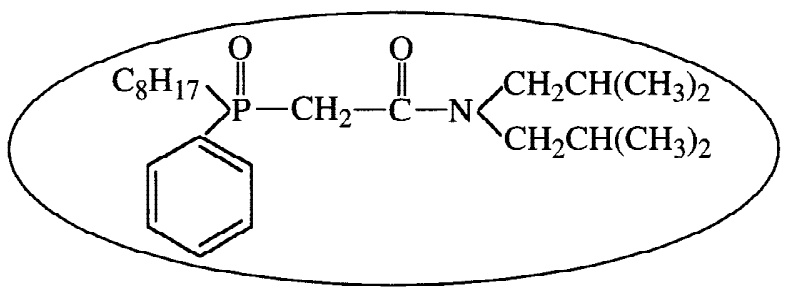

CMPO (octyl(phenyl)-N, N-diisobutylcarbamoylmethylphosphine oxide)

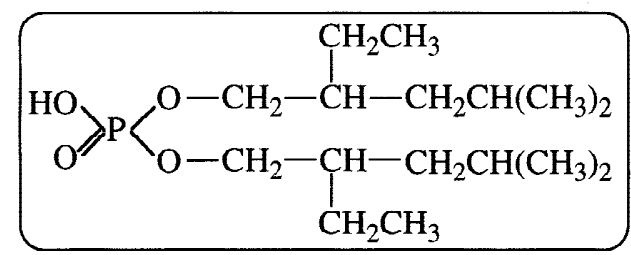

HDEHP (di(2-ethylhexyl)phosphoric acid)

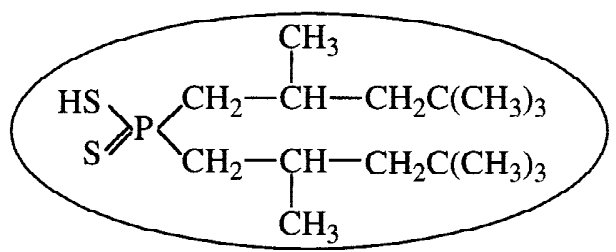

Cyanex 301 (bis(2,4,4-trimethylpentyl)dithiophosphinic acid)

Fig. 1. Chemical structures of the extractants.

of 0.69 were used. To support the extractants, an inert copolymer of formylstyrene and divinylbenzene was synthesized and embedded in the pores of the silica particles. The preparatory flow sheet of the polymerimmobilized silica particles $\left(\mathrm{SiO}_{2}-\mathrm{P}\right)$ is illustrated in Fig. 2. The silica particles were put into a glass flask placed in a rotary evaporator. The flask was evacuated by a vacuum pump, and a mixture of the monomers (85 wt $\% \mathrm{~m} / \mathrm{p}$-formylstyrene and $15 \mathrm{wt} \% \mathrm{~m} / \mathrm{p}$-divinylbenzene), initiators ( $\alpha, \alpha$-azobisisobutyronitrile and $1,1^{\prime}$-azobiscyclohexane-1-carbonitrile), and diluents (1,2,3-trichloropropane and $\mathrm{m}$-xylene) was sucked into the flask through a rubber tube. The flask was rotated continuously so that the mixture would soak completely into the pores of the silica particles and then filled with $\mathrm{N}_{2}$ gas. The flask was maintained in a silicone oil bath and then heated at $363 \mathrm{~K}$ for $20 \mathrm{~h}$. The grafted material $\left(\mathrm{SiO}_{2}-\mathrm{P}\right)$ was washed with acetone and water and then dried overnight at $323 \mathrm{~K}$. The content of the inert copolymer, formylstyrene-divinylbenzene, in the $\mathrm{SiO}_{2}-\mathrm{P}$ particles obtained was $17.6 \mathrm{wt} \%$ measured by means of thermogravimetric analysis (TGA).

The extractants, CMPO, HDEHP, and Cyanex 301, were impregnated into the $\mathrm{SiO}_{2}-\mathrm{P}$ particles. CMPO and HDEHP were used as commercially available products without further purification. A commercial Cyanex 301 product (purity $77.2 \%$ ) was purified as previously 


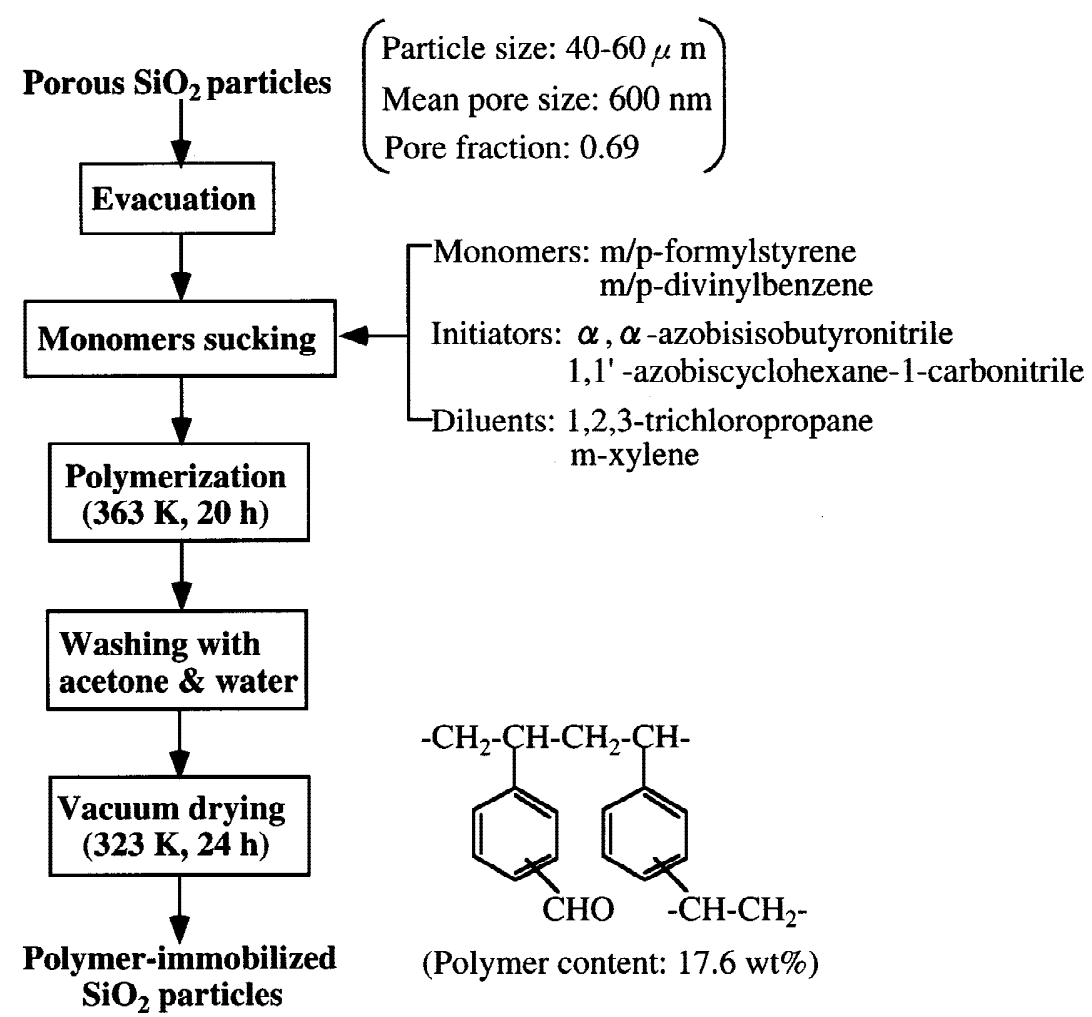

Fig. 2. Preparatory flow sheet of the polymer-immobilized silica particles $\left(\mathrm{SiO}_{2}-\mathrm{P}\right)$.

described, ${ }^{18,19}$ and the purity of the Cyanex 301 obtained was $99.5 \%$. The impregnation procedure of the extractants into the $\mathrm{SiO}_{2}-\mathrm{P}$ particles is as follows: $\sim 5$ to $7 \mathrm{~g}$ of an extractant (CMPO, HDEHP, or Cyanex 301) was placed in a glass flask and dissolved using $20 \mathrm{~cm}^{3}$ of dichloromethane as a diluent. Subsequently, $10 \mathrm{~g}$ of the dried $\mathrm{SiO}_{2}-\mathrm{P}$ particles was added to the solution and was shaken mechanically for $2 \mathrm{~h}$ at $298 \mathrm{~K}$. The resulting mixture was filtered and washed with a large amount of water over a sintered glass funnel to remove the diluent. The filter cake was then dried in vacuo overnight at 323 to $333 \mathrm{~K}$, and the silica-based extraction resin was obtained. The amount of impregnated extractant was measured by TGA, and the values were found to be 0.4 to 0.6 $\mathrm{g} / \mathrm{g} \mathrm{SiO}_{2}-\mathrm{P}$. To obtain a polymer-based extraction resin for the comparison experiments to evaluate the adsorption kinetics, the HDEHP extractant was impregnated into a polymeric beads material, Amberlite XAD-7 (mean particle size: $450 \mu \mathrm{m}$ ), which has been widely employed as a support of extraction resins, ${ }^{15,20}$ by the aforementioned impregnation procedure.

\section{Adsorption Experiment}

All distribution coefficients $\left(K_{d}\right)$ were measured by batch adsorption experiments, and the $K_{d}$ values for radionuclides were determined radiometrically. In a batch adsorption experiment, a weighed amount of extraction resin (typically, $0.25 \mathrm{~g}$ ) was combined in a glass vial with Teflon stopper with a measured volume (typically, $5 \mathrm{~cm}^{3}$ ) of an aqueous solution spiked with a trace amount $\left(\sim 10^{-7} M\right)$ of the radionuclides, ${ }^{241} \mathrm{Am},{ }^{153} \mathrm{Gd},{ }^{152} \mathrm{Eu}$, and ${ }^{139} \mathrm{Ce}$. The resultant mixture was shaken mechanically for more than $1 \mathrm{~h}$. The mixture was then centrifuged until the supernatant was free from suspended extraction resin and $1-\mathrm{cm}^{3}$ aliquots of the liquid were sampled for analysis. The gamma activity of the radionuclides was determined by a gamma-ray spectrometer with a $\mathrm{Ge}$ detector (Ortec). The lines at energies of 59, 97,122 , and $166 \mathrm{keV}$ were used for evaluating the ${ }^{241} \mathrm{Am}$, ${ }^{153} \mathrm{Gd},{ }^{152} \mathrm{Eu}$, and ${ }^{139} \mathrm{Ce}$, respectively. Care was taken during measurements to ensure that the pulse rates were generally at least 10000 to maintain the statistical error of individual measurements on the order of $1 \%$. The distribution coefficient was calculated by

$$
\begin{aligned}
K_{d} & =\frac{C_{0}-C_{S}}{C_{S}} \times \frac{V_{S}}{W_{R}} \\
& =\frac{A_{0}-A_{S}}{A_{S}} \times \frac{V_{S}}{W_{R}}\left(\mathrm{dm}^{3} / \mathrm{kg}\right),
\end{aligned}
$$


where

$$
\begin{aligned}
C_{0}\left(A_{0}\right)= & \text { nuclide concentration (activity) in the } \\
& \text { aqueous phase before adsorption } \\
C_{S}\left(A_{S}\right)= & \text { nuclide concentration in the aqueous phase } \\
& \text { after adsorption } \\
W_{R}= & \text { weight of the dry extraction resin }(\mathrm{kg}) \\
V_{S}= & \text { volume of the aqueous phase }\left(\mathrm{dm}^{3}\right) .
\end{aligned}
$$

The details of distribution coefficient measurements for stable nuclides were given in previous articles. ${ }^{10,12}$

\section{Separation Experiment}

Separation experiments for simulated HLW solutions were carried out using a Pyrex-glass column with 10-mm inner diameter and 200-mm length. Figure 3 shows a schematic of the column apparatus. An extraction resin (dry weight: 7.0 to $7.5 \mathrm{~g}$ ) was transferred to the column in the slurry state under 2 to 3 bars of $\mathrm{N}_{2}$ pressure. The volume of the resin bed $(B V)$ was $\sim 11.5$ to $12.0 \mathrm{~cm}^{3}$. The column and the throughput solutions were kept at a constant temperature with heated water jackets. Prior to the chromatographic operation, the extraction resin was conditioned by passing $100 \mathrm{~cm}^{3}$ of a blank solution with the same $\mathrm{pH}$ (acid concentration) as in the simulated HLW solution through the column. In the separation experiments using Cyanex 301-impregnated extraction resin, $20 \mathrm{~cm}^{3}$ of a simulated HLW solution ( $\mathrm{pH} 4.0$ ) containing trace amounts of ${ }^{241} \mathrm{Am},{ }^{153} \mathrm{Gd},{ }^{152} \mathrm{Eu}$, and ${ }^{139} \mathrm{Ce}, 1 M \mathrm{NaNO}_{3}$, and a macro amount of $\mathrm{Eu}(\mathrm{III})$ $\left(10^{-2} M\right)$ was applied to the column at a constant flow velocity of $1.0 \mathrm{~cm}^{3} / \mathrm{min}(0.76 \mathrm{~m} / \mathrm{h})$ by a highperformance liquid chromatography metering pump. The $20 \mathrm{~cm}^{3}$ of $\mathrm{HNO}_{3}$ acidic solution with $\mathrm{pH} 4.0$ was fed to the column as the rinse solution to wash the column and the extraction resin. Subsequently, $30 \mathrm{~cm}^{3}$ of $0.1 M \mathrm{HNO}_{3}$ was supplied to the column as the eluent solution. The effluents from the column were collected by an autofractional collector in $3-\mathrm{cm}^{3}$ aliquots. The gamma activity of the radionuclides in each fraction was counted by the gamma spectrometer as previously described. In the separation experiments using CMPO-impregnated extraction resin, a simulated HLW solution containing $5 \times 10^{-3} M$ of $\operatorname{Ln}(\mathrm{III})$, some typical FPs, and $3 \mathrm{MHNO}_{3}$

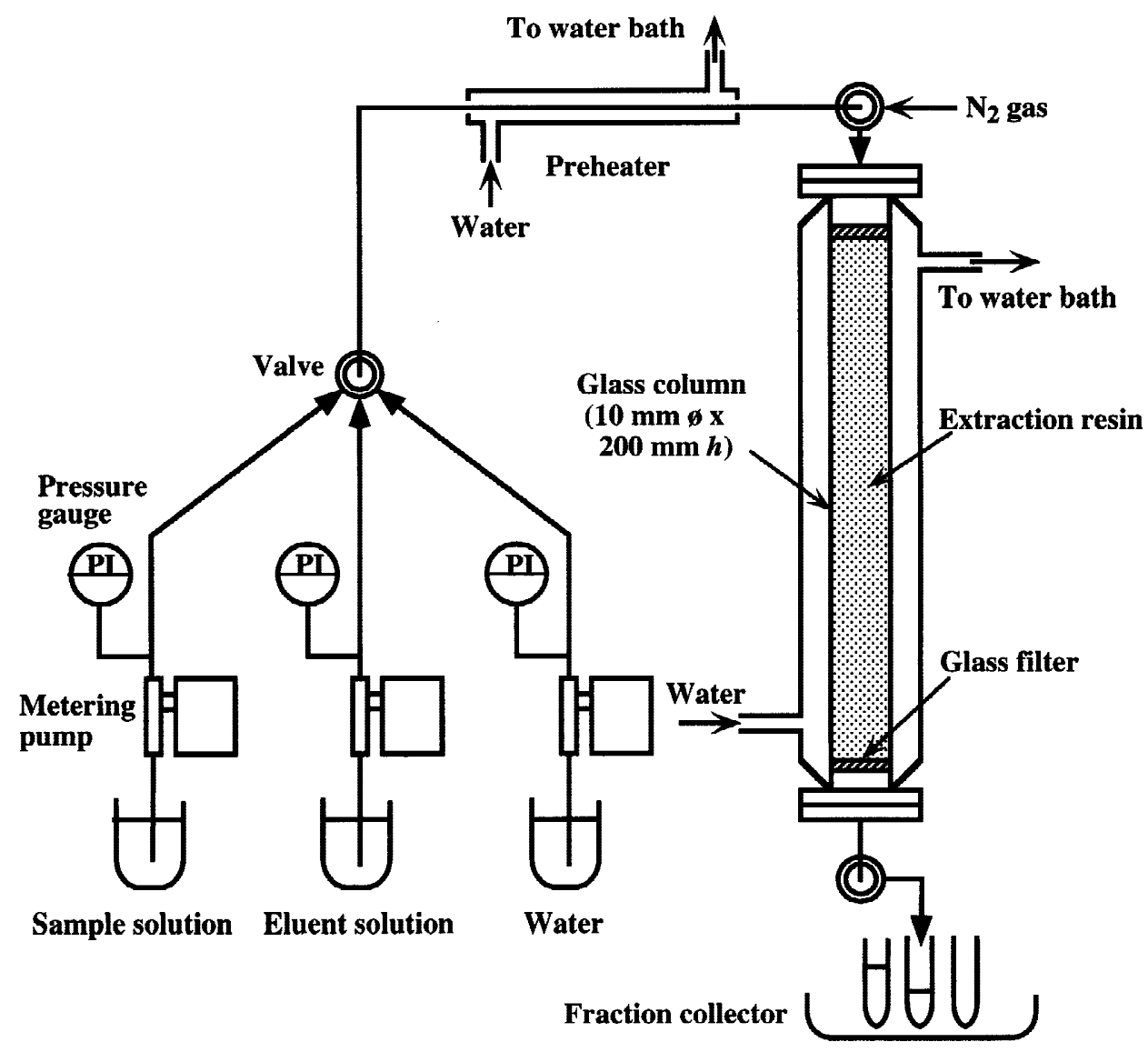

Fig. 3. Schematic of the column apparatus for separation experiments. 
was used. Distilled water was utilized as the eluent. The metal concentrations in the effluents were determined by inductively coupled argon plasma spectroscopy (Shimadzu ICPS-1000III).

\section{RESULTS AND DISCUSSION}

\section{Adsorption Characteristics}

According to previous studies, $3,16,21,22$ the adsorption reactions of trivalent metal ions onto CMPO-, HDEHP(HA)-, and Cyanex 301(HX)-impregnated extraction resins can be expressed by Eqs. (2), (3), and (4), respectively, which are the same as those for liquidliquid extraction:

$$
\begin{aligned}
\mathrm{M}^{3+}+3 \mathrm{NO}_{3}^{-}+3 \mathrm{CMPO} & =\mathrm{M}\left(\mathrm{NO}_{3}\right)_{3}(\mathrm{CMPO})_{3}, \\
\mathrm{M}^{3+}+3(\mathrm{HA})_{2} & =\mathrm{M}\left(\mathrm{HA}_{2}\right)_{3}+3 \mathrm{H}^{+}
\end{aligned}
$$

and

$$
\mathrm{M}^{3+}+2(\mathrm{HX})_{2}=\mathrm{MX}_{3}(\mathrm{HX})+3 \mathrm{H}^{+} .
$$

To evaluate the adsorption kinetics of the silicabased extraction resins, the time evolution of $\mathrm{Nd}$ (III) adsorption from $0.1 M \mathrm{HNO}_{3}$ solution onto the HDEHPimpregnated extraction resin was measured, and the results are illustrated in Fig. 4. As can be seen, the Nd(III) ad- sorption onto the HDEHP/XAD-7 resin was very slow and still continued after $20 \mathrm{~h}$. On the other hand, with $\mathrm{HDEHP} / \mathrm{SiO}_{2}-\mathrm{P}$ resin, the adsorption is quite rapid and reached an equilibrium state after $\sim 30 \mathrm{~min}$. The adsorption kinetics of metal ions onto impregnated extraction resins has been investigated by some authors. ${ }^{23,24}$ It is well known that in many cases, the adsorption kinetics is limited by the diffusion step inside the resin, and a reduction in the particle size of an extraction resin will lead to more rapid kinetics. The particle size of HDEHP/ $\mathrm{SiO}_{2}-\mathrm{P}$ resin is 40 to $60 \mu \mathrm{m}$, which is $\sim \frac{1}{10}$ of the HDEHP/ $\mathrm{XAD}-7$ resin, so the rapid adsorption kinetics shown by $\mathrm{HDEHP} / \mathrm{SiO}_{2}-\mathrm{P}$ resin is considered to result mainly from the fine particle size.

The leakage behavior of the HDEHP extractant from the extraction resin during the adsorption experiment is also shown in Fig. 4. It is apparent that the leaked amount was very slight $(<1 \%)$ and did not increase with time.

Figure 5 shows the effect of $\mathrm{HNO}_{3}$ concentration on the adsorption of ${ }^{241} \mathrm{Am}$ (III), ${ }^{153} \mathrm{Gd}$ (III), ${ }^{152} \mathrm{Eu}$ (III), and ${ }^{139} \mathrm{Ce}$ (III) from nitric acid solution onto $\mathrm{HDEHP} / \mathrm{SiO}_{2}-\mathrm{P}$ resin. Note that the adsorption of these nuclides significantly decreased with increasing $\mathrm{HNO}_{3}$ concentration. This is due to the increase of $\mathrm{H}^{+}$concentration and can be explained by the equilibrium of Eq. (3). As shown in Fig. 5, the heavy Ln(III), i.e., Gd(III) and Eu(III), presents stronger adsorption, and the separation factor (the ratio of distribution coefficient) between these $\operatorname{Ln}(\mathrm{III})$

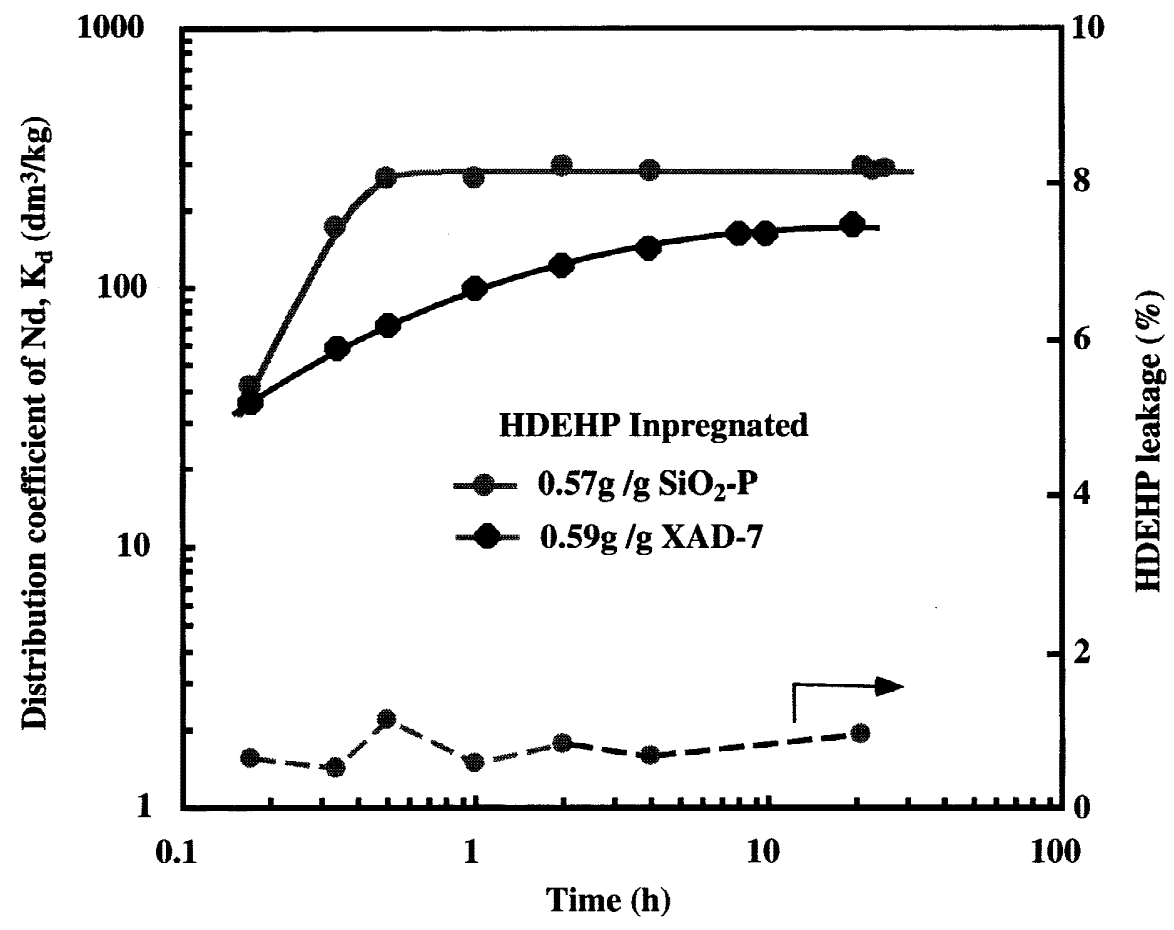

Fig. 4. Time evolution of $\mathrm{Nd}(\mathrm{III})$ adsorption from nitric acid solution onto HDEHP-impregnated resin $\left(0.57 \mathrm{~g} \mathrm{HDEHP} / \mathrm{SiO}_{2}-\mathrm{P}\right.$, $\left.0.1 \mathrm{~mol} / \mathrm{dm}^{3} \mathrm{HNO}_{3}, 298 \mathrm{~K}\right)$. 


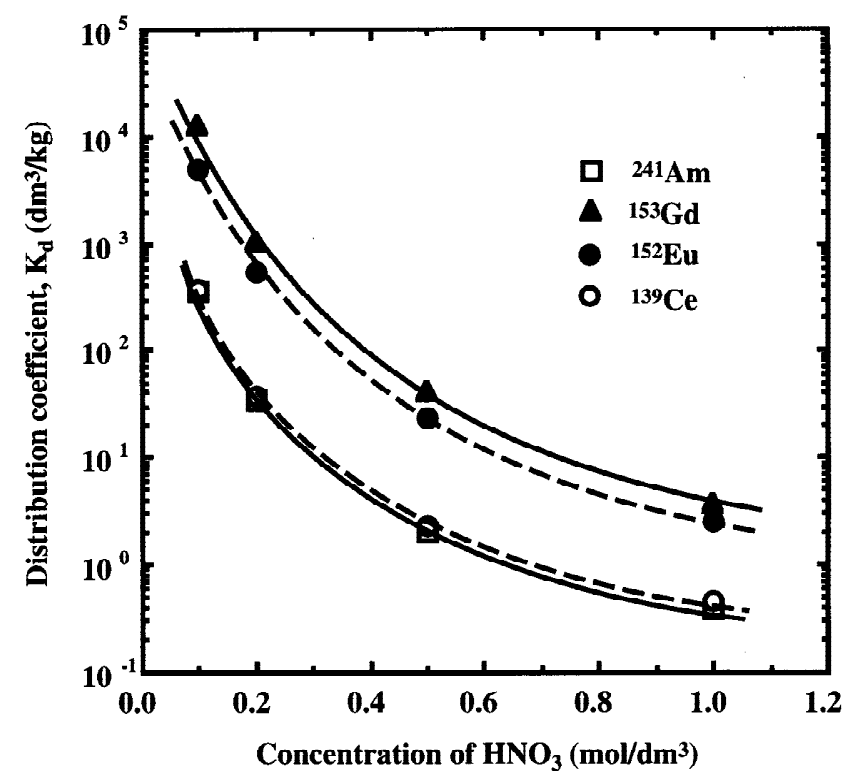

Fig. 5. Effects of nitric acid concentration on the adsorption of $\mathrm{Am}(\mathrm{III})$ and $\mathrm{Ln}(\mathrm{III})$ onto HDEHP-impregnated resin (0.57 g HDEHP / $\left.\mathrm{SiO}_{2}-\mathrm{P}, 298 \mathrm{~K}\right)$.

and $\mathrm{Am}(\mathrm{III})$ is $\sim 10$. However, because the distribution coefficient of Am(III) is almost the same as that of $\mathrm{Ce}$ (III), a light $\mathrm{Ln}$ (III) in the experimental range of $\mathrm{HNO}_{3}$ concentration, we conclude that the separation between Am(III) and the light Ln(III), such as La(III), Ce(III), $\mathrm{Nd}$ (III), which form the majority of FP lanthanides in the HLW solution, is very difficult by extraction chromatography using the $\mathrm{HDEHP} / \mathrm{SiO}_{2}-\mathrm{P}$ resin.

Figure 6 illustrates the relationship between the distribution coefficient of ${ }^{241} \mathrm{Am}(\mathrm{III}),{ }^{153} \mathrm{Gd}(\mathrm{III}),{ }^{152} \mathrm{Eu}(\mathrm{III})$, and ${ }^{139} \mathrm{Ce}(\mathrm{III})$ plotted against the $\mathrm{pH}$ value with Cyanex $301 / \mathrm{SiO}_{2}-\mathrm{P}$ resin. It was found that $\mathrm{Am}$ (III) showed quantitative adsorption from $\mathrm{pH} \sim 3.0$ onward, and the adsorption increased dramatically with increasing $\mathrm{pH}$ value. However, the trivalent lanthanide nuclides showed only slight adsorption at all the experimental $\mathrm{pH}$ values, and the separation factor for $\mathrm{Am}$ (III)/Ln(III) is up to nearly 1000 at $\mathrm{pH} 4$ to 4.5. This indicated that the Cyanex 301/ $\mathrm{SiO}_{2}-\mathrm{P}$ resin shows significantly high adsorption selectivity for Am(III) compared to trivalent lanthanides, and the results agreed well with those reported in liquidliquid extraction. ${ }^{16,18}$ On the other hand, the previous experiments indicated that ${ }^{244} \mathrm{Cm}$ (III) can also be extracted by purified Cyanex 301 and showed an extraction behavior similar to Am(III) (Ref. 18). From these results, it is expected that $\mathrm{Am}$ (III) and $\mathrm{Cm}$ (III) can be effectively separated from $\mathrm{Ln}$ (III) by means of column chromatography using the Cyanex $301 / \mathrm{SiO}_{2}-\mathrm{P}$ resin. The mechanism for the highly selective adsorption of $\mathrm{Am}$ (III) and Cm(III) in comparison to $\mathrm{Ln}$ (III) has not yet been clarified and is assumed to result partly from the relatively stronger com- plex formation (metal-ligand covalent bonding) between the transplutonides and the soft donor (S) (Ref. 18).

\section{Separation Behavior}

Since CMPO, a bifunctional organophosphorus compound, can efficiently extract trivalent actinides and lanthanides from aqueous solution containing concentrated nitric acid, it has been extensively studied for the coextraction of MA-Ln from HLW solutions. ${ }^{1-3,14}$ To examine the separation behavior of $\mathrm{Ln}$ (III) from other FPs, a separation experiment for a simulated HLW solution containing typical $\operatorname{Ln}(\mathrm{III})$ and FPs was carried out using a $\mathrm{CMPO} / \mathrm{SiO}_{2}-\mathrm{P}$ packed column. Figure 7 shows the elution curves of the column chromatography for the sample solution containing $\sim 5 \times 10^{-3} M$ of $\mathrm{Nd}$ (III), Gd(III), $\mathrm{Y}(\mathrm{III}), \mathrm{Cs}(\mathrm{I}), \mathrm{Sr}(\mathrm{II})$, and $\mathrm{Ru}(\mathrm{III})$ and $3 \mathrm{MHNO}_{3}$. As can be seen, $\mathrm{Cs}(\mathrm{I})$ and $\mathrm{Sr}$ (II) showed no adsorption. These elements leaked out with the sample solution and the $3 \mathrm{M}$ $\mathrm{HNO}_{3}$ rinse solution. Most of the $\mathrm{Ru}(\mathrm{III})$ was not adsorbed by the extraction resin either and showed a behavior similar to $\mathrm{Cs}(\mathrm{I})$ and $\mathrm{Sr}(\mathrm{II})$. However, its small portion $(\sim 12 \%)$ was adsorbed and was not eluted out by water. This is probably due to the hydrolysis of $\mathrm{Ru}(\mathrm{III})$ inside the resin, and the elution method for the adsorbed $\mathrm{Ru}$ (III) must be further investigated. On the other hand, all the Ln(III) strongly adsorbed onto the resin and the adsorbed $\operatorname{Ln}(\mathrm{III})$ were eluted off efficiently by using only water. The elution effect of $\mathrm{Ln}(\mathrm{III})$ is considered to result from the decomposition of the $\mathrm{Ln}$ (III) complex, as shown in Eq. (2) with the decrease of $\mathrm{NO}_{3}^{-}$

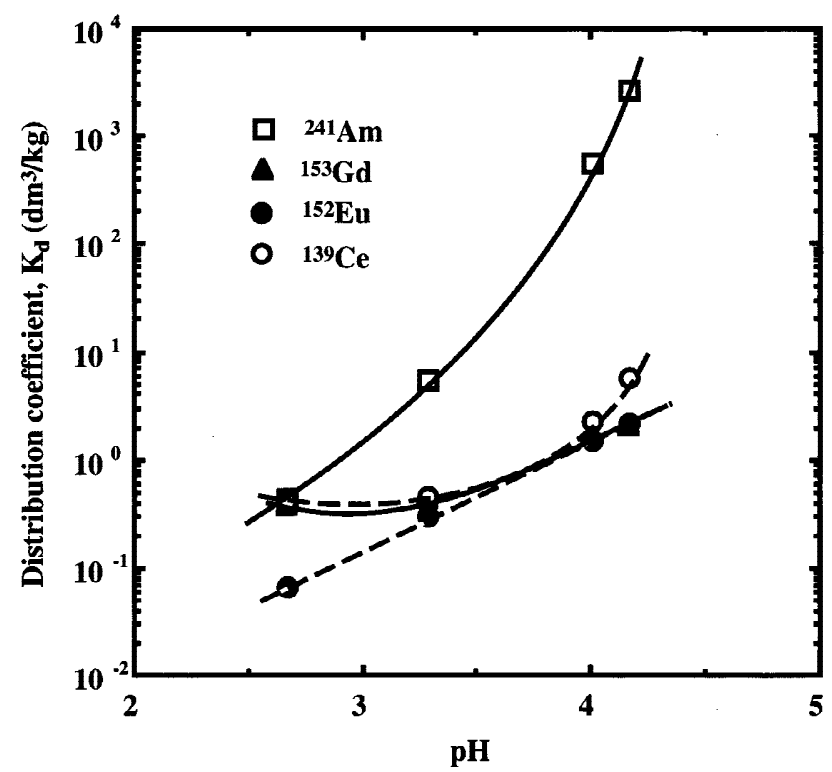

Fig. 6. Effects of $\mathrm{pH}$ on the adsorption of $\mathrm{Am}$ (III) and $\mathrm{Ln}$ (III) onto Cyanex 301-impregnated resin [0.46 g Cyanex $\left.301 / \mathrm{SiO}_{2}-\mathrm{P}, 298 \mathrm{~K}, 1.0 \times 10^{-3} \mathrm{~mol} / \mathrm{dm}^{3} \mathrm{Eu}(\mathrm{III})\right]$. 


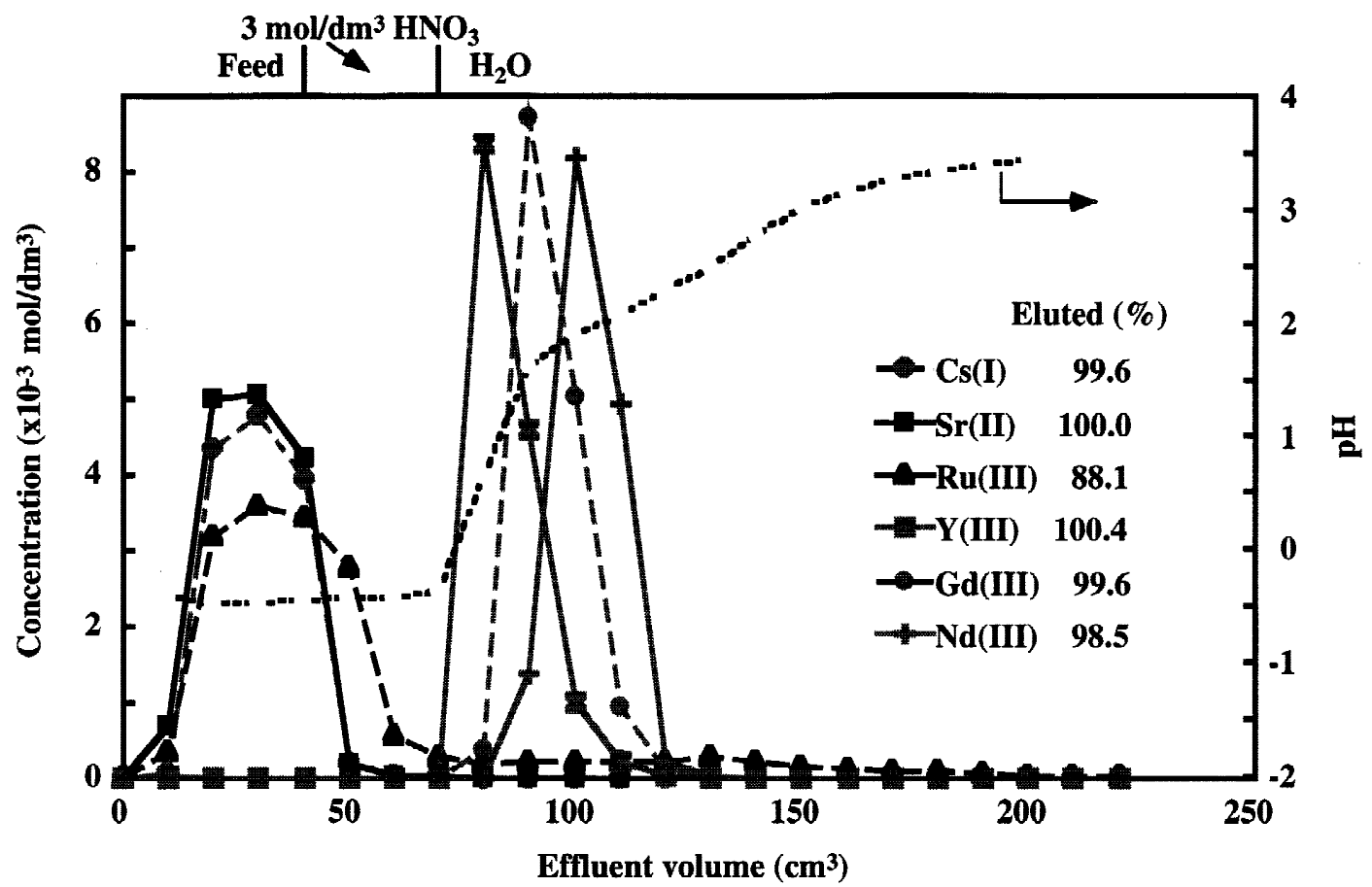

Sample solution: $5.0 \times 10^{-3} \mathrm{~mol} / \mathrm{dm}^{3}$ metal ions, $3.0 \mathrm{~mol} / \mathrm{dm}^{3} \mathrm{HNO}_{3}$

Fig. 7. Results of separation experiment for a simulated HLW solution using CMPO-impregnated resin $\left(0.57 \mathrm{~g} \mathrm{CMPO} / \mathrm{SiO}_{2}-\mathrm{P}\right.$; $323 \mathrm{~K}$; flow rate, $0.76 \mathrm{~m} / \mathrm{h})$.

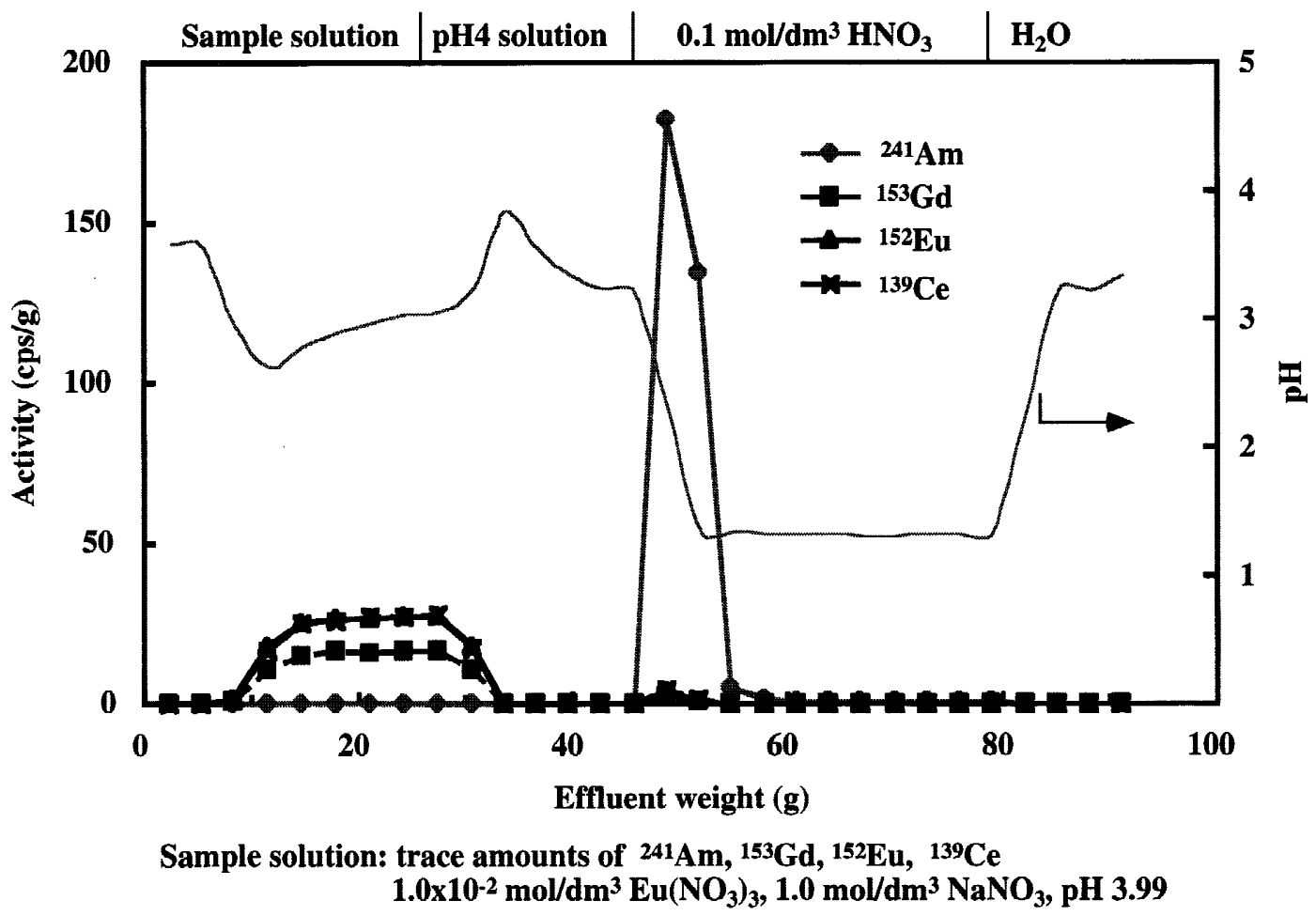

Fig. 8. Results of separation experiment for a sample solution containing Am(III) and Ln(III) using a new Cyanex 301impregnated resin (0.46 g Cyanex 301/ $\mathrm{SiO}_{2}-\mathrm{P}$; $298 \mathrm{~K}$; flow rate, $0.76 \mathrm{~m} / \mathrm{h}$ ). 
concentration in the resin bed by supplying water to the column. The elution bands observed are quite narrow and showed very slight tailing, which indicates that the silicabased extraction resin has a rapid kinetics. Moreover, no pressure loss inside the column was observed during solution supply. However, because of the low selectivity of CMPO for MA(III)/Ln(III) (Refs. 1, 2, 3, and 15), distinct separation between MA(III) and Ln(III) cannot be expected by using $\mathrm{CMPO} / \mathrm{SiO}_{2}-\mathrm{P}$ resin.

Figure 8 shows the results of a separation experiment for the sample solution ( $\mathrm{pH} 3.99)$ containing trace amounts of ${ }^{241} \mathrm{Am}$ (III), ${ }^{153} \mathrm{Gd}(\mathrm{III}),{ }^{152} \mathrm{Eu}$ (III), ${ }^{139} \mathrm{Ce}$ (III), $10^{-2} M \mathrm{Eu}(\mathrm{III})$, and $1 M \mathrm{NaNO}_{3}$ using the column packed with Cyanex 301-impregnated resin. In this experiment, a newly purified (within $10 \mathrm{~h}$ of preparation) Cyanex 301/ $\mathrm{SiO}_{2}-\mathrm{P}$ resin was employed. Twenty cubic centimetres of the sample solution, $20 \mathrm{~cm}^{3}$ of $\mathrm{HNO}_{3}$ acidic solution with $\mathrm{pH} 4.0$, and $30 \mathrm{~cm}^{3}$ of $0.1 M \mathrm{HNO}_{3}$ were successively applied to the column. It was found that the Am(III) was completely adsorbed by the resin, while only a very small portion $(\sim 1$ to $2 \%)$ of $\operatorname{Ln}$ (III) was adsorbed. The adsorbed Am(III) was efficiently eluted off by $0.1 \mathrm{M}$ $\mathrm{HNO}_{3}$ solution, corresponding to the decrease of the $\mathrm{pH}$ value. The results exhibited good agreement with the adsorption behavior shown in Fig. 6.
Since it has been reported that purified Cyanex 301 shows low stability due to oxidation and decomposition, ${ }^{18,25,26}$ we have conducted a separation experiment using an "aged" Cyanex 301/ $\mathrm{SiO}_{2}-\mathrm{P}$ to examine the effect of this on the separation performance. Figure 9 illustrates the experimental results for the same sample solution as utilized in the experiment of Fig. 8 using the Cyanex $301 / \mathrm{SiO}_{2}-\mathrm{P}$ resin, which had been prepared 4 weeks earlier. Note that both Am(III) and Ln(III) showed two occurrence peaks. Most of the Am(III) ( 90\%) was adsorbed and eluted off by $0.1 \mathrm{M} \mathrm{HNO}_{3}$ solution. However, a portion (20 to $40 \%$ ) of each Ln(III) was also adsorbed and eluted out together with Am(III). This effect is considered to be caused by impurities such as $\mathrm{R}_{2} \mathrm{PSOH}$ and $\mathrm{R}_{2} \mathrm{POOH}$, which were produced by the oxidation of $\mathrm{R}_{2} \mathrm{PSSH}$. It is known that these oxygen-containing organophosphoric compounds show high adsorbability for Ln(III). ${ }^{18,25,26}$

These separation experiments demonstrated that Am(III) can be effectively separated from a macro amount of $\mathrm{Ln}$ (III) in simulated HLW solution with $\mathrm{pH} 4$ by using a newly purified Cyanex $301 / \mathrm{SiO}_{2}-\mathrm{P}$ resin. However, the separation performance is very sensitive to the purity of Cyanex 301, and the improvement of its stability is an important task for practical utilization.

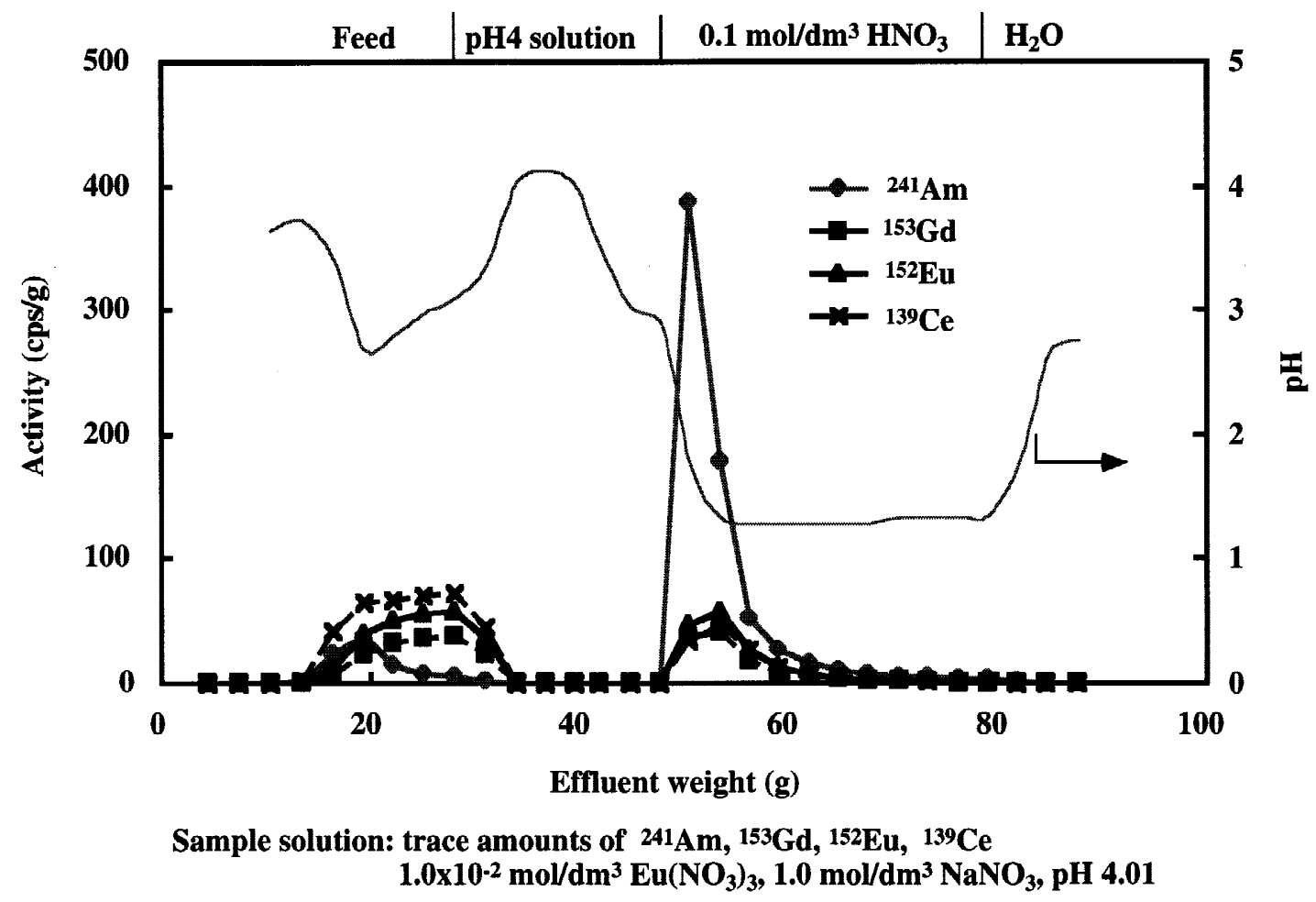

Fig. 9. Results of separation experiment for a sample solution containing Am(III) and Ln(III) using an old Cyanex 301impregnated resin (0.46 g Cyanex 301/ $\mathrm{SiO}_{2}-\mathrm{P} ; 298 \mathrm{~K}$; flow rate, $\left.0.76 \mathrm{~m} / \mathrm{h}\right)$. 


\section{An Advanced Separation Process}

Based on the preceding experimental results, a separation process, as shown in Fig. 10, has been proposed for the isolation of $\mathrm{Am}$ and $\mathrm{Cm}$ from the nitrate acidic HLW solution by extraction chromatography using the novel silica-based extraction resins. In the first step, the HLW solution is applied to the column packed with $\mathrm{CMPO} / \mathrm{SiO}_{2}-\mathrm{P}$ resin, and the adsorptive Am(III), $\mathrm{Cm}(\mathrm{III})$, and $\mathrm{Ln}(\mathrm{III})$ are adsorbed by the resin. In the second step, most FPs (non- or weakly adsorptive FPs) such as $\mathrm{Cs}(\mathrm{I}), \mathrm{Sr}$ (II), and $\mathrm{Ru}$ (III) are washed off by concentrated $\mathrm{HNO}_{3}$, while leaving the adsorptive elements in the column. In the third step, the adsorbed Am(III), $\mathrm{Cm}$ (III), and $\mathrm{Ln}$ (III) are eluted off the column by dilute $\mathrm{HNO}_{3}$ or water, and the $\mathrm{pH}$ value in the eluate is $\sim 2.0$ to 2.5. In the fourth step, the $\mathrm{pH}$ in the eluate is adjusted to 3.5 to 4.0 by the addition of an alkali such as sodium hydroxide. Subsequently, the resulting solution is introduced into the column packed with Cyanex 301/ $\mathrm{SiO}_{2}-\mathrm{P}$ resin, which adsorbs $\mathrm{Am}(\mathrm{III})$ and $\mathrm{Cm}(\mathrm{III})$ selectively (step 5). In the sixth step, a nitrate acidic solution with $\mathrm{pH} 3.5$ to 4.0 is supplied to the column to wash out the

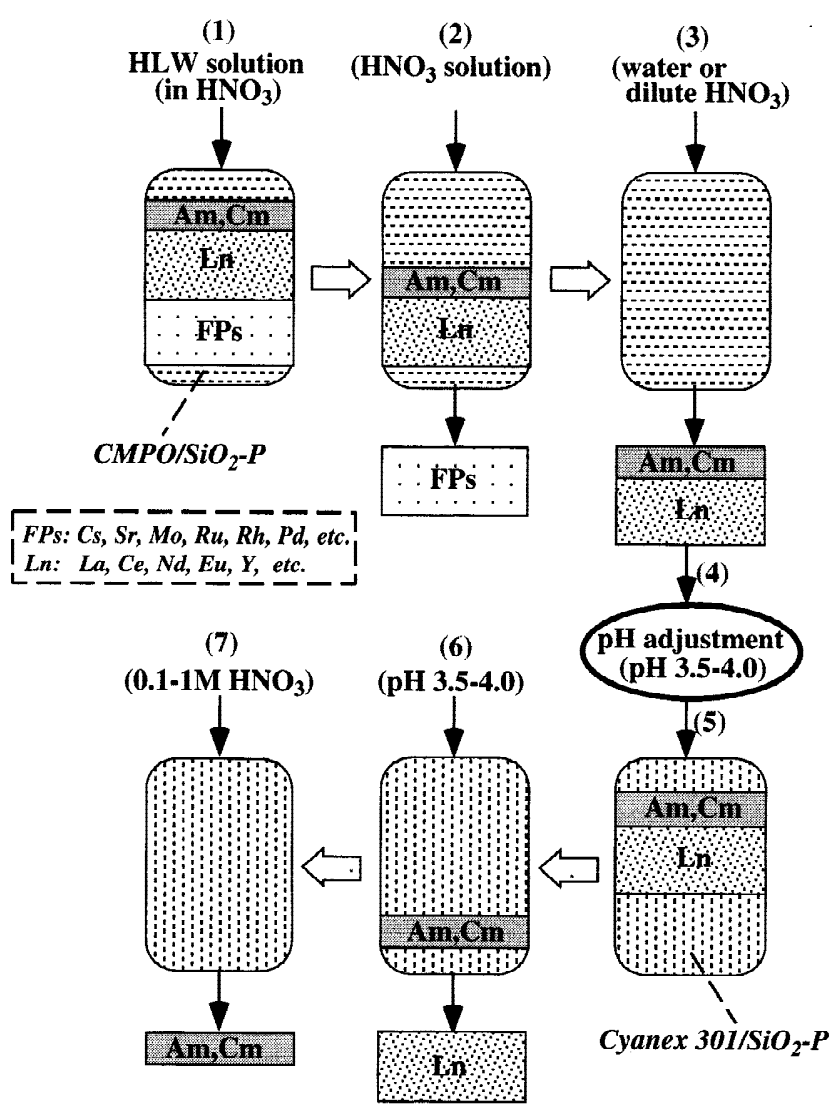

Fig. 10. A proposed process for the separation of minor actinides from HLW solution by extraction chromatography. nonadsorptive $\mathrm{Ln}$ (III). In the final step, the adsorbed Am(III) and $\mathrm{Cm}$ (III) are then eluted out by using a dilute $\mathrm{HNO}_{3}$ solution. The conceptual design and evaluation for this process is under way.

\section{CONCLUSIONS}

The novel silica-based extraction resins were prepared by impregnating CMPO, HDEHP, or purified Cyanex 301 into the styrene-divinylbenzene copolymer, which is immobilized in porous silica particles. The adsorption characteristics of Am(III) and Ln(III) from nitrate acidic solutions onto the extraction resins were investigated, and their separation behavior from simulated HLW solutions was demonstrated by extraction chromatography.

In the separation experiment for a simulated HLW solution containing typical $\mathrm{Ln}(\mathrm{III}), \mathrm{FPs}$, and $3 M \mathrm{HNO}_{3}$ using a $\mathrm{CMPO} / \mathrm{SiO}_{2}-\mathrm{P}$ resin-packed column, the adsorbed Ln(III) ions were effectively eluted off by water and separated from other FPs such as $\mathrm{Cs}(\mathrm{I}), \mathrm{Sr}(\mathrm{II})$, and $\mathrm{Ru}(\mathrm{III})$.

Am(III) showed almost the same adsorbability as $\mathrm{Ce}$ (III) onto $\mathrm{HDEHP} / \mathrm{SiO}_{2}-\mathrm{P}$ resin in 0.1 to $1.0 \mathrm{M} \mathrm{HNO}_{3}$ solutions. The separation between Am(III) and the light $\mathrm{Ln}(\mathrm{III})$, such as $\mathrm{La}(\mathrm{III}), \mathrm{Ce}(\mathrm{III})$, and $\mathrm{Nd}(\mathrm{III})$, is very difficult using $\mathrm{HDEHP} / \mathrm{SiO}_{2}-\mathrm{P}$ resin.

Am(III) exhibited significantly strong adsorption onto purified Cyanex 301/ $\mathrm{SiO}_{2}-\mathrm{P}$ resin at a $\mathrm{pH}$ higher than 3.5, while Ln(III) showed only slight adsorption, and the separation factor for Am(III)/Ln(III) is up to nearly 1000 . Satisfactory separation between Am(III) and a macro amount of Ln(III) from simulated HLW solution with $\mathrm{pH} 4$ was achieved by using a newly purified Cyanex $301 / \mathrm{SiO}_{2}-\mathrm{P}$ resin. However, the separation performance is very sensitive to the purity of Cyanex 301, and the improvement of its stability is an important task for practical utilization.

\section{ACKNOWLEDGMENTS}

This work was financed by the Science and Technology Agency of Japan. The authors gratefully acknowledge the agency's permission to publish this work. The authors also wish to thank K. Scharf from ISR-3 at Forschungszentrum Jülich GmbH for assistance in the preparation of the radioactive solutions.

\section{REFERENCES}

1. Z. KOLARIK, "Current European Research on the Separation of Actinides from High-Level Radioactive Wastes," $J$. Nucl. Fuel Cycle Envi., 5, 1, 21 (1998).

2. E. P. HORWITZ, H. DIAMOND, R. C. GATRONE, K. L. NASH, and P. G. RICKERT, "A New Class of Aqueous 
Complexing Agents for Use in Solvent Extraction Processes," Solvent Extraction 1990, p. 357, T. SEKINE, Ed., Elsevier Science Publishers, New York (1990).

3. Y. KOMA, M. WATANABE, S. NEMOTO, and Y. TANAKA, "Trivalent f-Element Intra-group Separation by Solvent Extraction with CMPO-complexant System," J. Nucl. Sci. Technol., 35, 130 (1998).

4. Y. ZHU and R. JIAO, "Chinese Experience in the Removal of Actinides from Highly Active Waste by Trialkylphosphine-Oxide Extraction," Nucl. Technol., 108, 361 (1994).

5. P. Y. CORDIER, C. RABBE, N. FRANCOIS, C. MADIC, and Z. KOLARIK, "Comparative Study of Some Nitrogen Bearing Ligands for the An(III)/Ln(III) Separation by LiquidLiquid Extraction," Proc. 2nd NUCEF Int. Symp., NUCEF'98, Hitachinaka, Japan, November 16-17, 1998, p. 278, Japan Atomic Energy Research Institute (1999).

6. Y. MORITA, I. YAMAGUCHI, T. FUJIWARA, H. KOIZUMI, and M. KUBOTA, "The First Test of 4-Group Partitioning Process with Real High-Level Liquid Waste At NUCEF," Proc. 2nd NUCEF Int. Symp., NUCEF'98, Hitachinaka, Japan, November 16-17, 1998, p. 491, Japan Atomic Energy Research Institute (1999).

7. G. MODOLO and R. ODOJ, "Synergistic Selective Extraction of Actinides(III) over Lanthanides from Nitric Acid Using New Aromatic Diorganyldithiophosphinic Acids and Neutral Organophosphorus Compounds," Solvent Extr. Ion Exch., 17, 33 (1999).

8. A. SUZUKI, “Japan's Program on Research and Development of Advanced Fuel Cycle Technologies," Proc. Int. Conf. Future Nuclear Systems, GLOBAL'99, Jackson Hole, Wyoming, August 29-September 3, 1999 (1999).

9. S. E. ION and P. D. WILSON, "Improved Aqueous Reprocessing Technology: Will the Financial and Environmental Performance Satisfy Future Requirements?" Proc. Int. Conf. Future Nuclear Systems, GLOBAL'99, Jackson Hole, Wyoming, August 29-September 3, 1999 (1999).

10. Y.-Z. WEI et al., "A Study on the Application of a Newly Developed Ion-Exchange Process to Spent-Nuclear-Fuel Reprocessing," Ion Exchange Developments and Applications, p. 174, J. A. GREIG, Ed., SCI, London (1996).

11. Y.-Z. WEI, M. YAMAGUCHI, M. KUMAGAI, Y. TAKASHIMA, T. HOSHIKAWA, and F. KAWAMURA, "Separation of Actinides from Simulated Spent Fuel Solutions by an Advanced Ion-Exchanger Process," J. Alloys and Compounds, 271-273, 693 (1998).

12. Y.-Z. WEI et al., "The Application of an Advanced Ion Exchange Process to Reprocessing Spent Nuclear Fuels (I)," J. Nucl. Sci. Technol., 35, 357 (1998).

13. Y.-Z. WEI, M. KUMAGAI, Y. TAKASHIMA, A. BRUGGEMAN and M. GYSEMAN, "A Rapid Elution Method of Tetravalent Plutonium from Anion Exchanger," J. Nucl. Sci. Technol., 36, 304 (1999).
14. J. D. NAVRATIL, A. MURPHY, and D. SUN, "Mixed Solvent Extraction-Annular Chromatographic Systems for f-Element Separation and Purification," Solvent Extraction 1990, p. 1151, T. SEKINE, Ed., Elsevier Science Publishers, New York (1990).

15. E. P. HORWITZ, R. CHIARIZIA, M. L. DIETZ, H. DIAMOND, and D. M. NELSON, "Separation and Preconcentration of Actinides from Acidic Media by Extraction Chromatography," Anal. Chim. Acta, 281, 361 (1993).

16. Y. ZHU, J. CHEN, and R. JIAO, "Extraction of Am(III) and Eu(III) from Nitrate Solution with Purified Cyanex 301," Solvent Extr. Ion Exch., 14, 61 (1996).

17. J. CHEN, Y. ZHU, and R. JIAO, "Separation of Am(III) from Fission Product Lanthanides by Bis(2,4,4-trimethylpentyl)dithiophosphinic Acid (HBTMPDTP) Extraction: Process Parameter Calculation," Nucl. Technol., 122, 64 (1998).

18. G. MODOLO and R. ODOJ, "Influence of the Purity and Irradiation Stability of Cyanex 301 on the Separation of Trivalent Actinides from Lanthanides by Solvent Extraction," $J$. Radioanal. Nucl. Chem., 228, 83 (1998).

19. J. CHEN, R. JIAO, and Y. ZHU, "Purification and Properties of Cyanex 301," Chinese J. Appl. Chem., 13, 2, 45 (1996) (in Chinese).

20. E. P. HORWITZ, M. L. DIETZ, D. M. NELSON, J. J. LAROSA, and W. D. FAIRMAN, "Concentration and Separation of Actinides from Urine Using a Supported Bifunctional Organophosphorus Extractant," Anal. Chim. Acta, 238, 263 (1990).

21. K. TAKESHITA, Y. TAKASHIMA, S. MATSUMOTO, and H. YAMANAKA, "Extraction of Cerium(III) by Polymer Gels Swollen with Bidentate Organophosphorus Compounds," J. Chem. Eng. Jpn., 28, 91 (1995).

22. K. L. NASH, "A Review of the Basic Chemistry and Recent Developments in Trivalent f-elements Separations," Solvent Extr. Ion Exch., 11, 729 (1993).

23. J. L. CORTINA and N. MIRALLES, "Kinetic Studies on Heavy Metal Ions Removal by Impregnated Resins Containing Di-(2,4,4-trimethylpentyl) Phosphinic Acid," Solvent Extr. Ion Exch., 15, 1067 (1997).

24. K. TAKESHITA, M. KUMAGAI, Y. TAKASHIMA, and S. MATSUMOTO, "Extraction of Cerium(III) by Solid Extractant Impregnated with Dihexyl-N, N-diethylcarbamoylmethylphosphonate," J. Chem. Eng. Jpn., 27, 52 (1994).

25. J. CHEN, R. JIAO, and Y. ZHU, "A Study on the Radiolytic Stability of Commercial and Purified Cyanex 301," Solvent Extr. Ion Exch., 14, 555 (1996).

26. M. OZAWA, C. HILL, and C. MADIC, "Trivalent Minor Actinide/Lanthanide Separation using Organothiophosphinic Acids (III) - Hydrolytic Stability of Cyanex 301 and Its Degradation Effect on Separation of Am/Eu," Summary of 1998 AESJ Autumn Mtg., Fukui, p. 674 (1998) (in Japanese). 
Yuezhou Wei (BS, mineral engineering, Central South University of Technology, China, 1983; MS, mineral engineering, Akita University, Japan, 1987; DEng, metallurgical engineering, Tohoku University, Japan, 1990) is a senior scientist in the Nuclear Chemical Engineering Center, Institute of Research and Innovation (IRI), Japan. His research interests include chemical separation for nuclear fuel reprocessing and radioactive waste management, electrochemistry of actinides, and synthesis of functional agents for actinides separation.

Mikio Kumagai (BS, 1970; MS, 1972; and DEng, 1977, chemical engineering, University of Tokyo) is the director and chief scientist of the Nuclear Chemical Engineering Center IRI, Japan. His research interests include nuclear fuel reprocessing, off-gas treatment, radioactive waste management, and process design.

Yoichi Takashima (BS, 1945, and DEng, 1956, chemical engineering, Tokyo Institute of Technology) is currently a senior advisor at IRI and a professor emeritus of Tokyo Institute of Technology. His research interests include centrifugal separation for uranium enrichment, nuclear fuel reprocessing, off-gas treatment, radioactive waste management, and geologic disposal.

Giuseppe Modolo (MS, 1990, and PhD, 1993, chemistry, Technical University Aachen, Germany) is employed at the Institute for Safety Research and Reactor Technology (ISR), the Research Center of Jülich (FZJ), Germany. His research interests include chemistry of the nuclear fuel cycle, partitioning and transmutation of long-lived radionuclides, and solvent extraction chemistry of actinide and lanthanide elements.

Reinhard Odoj (MS, 1974, and PhD, 1977, chemistry, University of Bonn, Germany) has been employed at FZJ since 1973. He is a professor of waste management in the nuclear fuel cycle at Rheinisch-Westfalische Technische Hochschule in Aachen, Germany, and the head of the Division for Nuclear Waste Management at the ISR of FZJ. His research interests include high-level liquidwaste vitrification, waste conditioning, and radiochemical separation of radionuclides for transmutation. 